\title{
INFÂNCIAS E CRIANÇAS RIBEIRINHAS DA AMAZÔNIA MARAJOARA: LINGUAGENS E PRÁTICAS CULTURAIS ${ }^{1}$
}

\author{
Simei Santos Andrade* \\ Tatiana do Socorro Corrêa Pacheco ${ }^{1 * *}$
}

\section{RESUMO}

“Infâncias e crianças ribeirinhas da Amazônia Marajoara: linguagens e práticas culturais" faz parte de uma investigação mais abrangente sobre infâncias na Amazônia, em andamento. A pesquisa foi realizada com 20 (vinte) crianças, na faixa etária de 5 a 11 anos, residentes no município de Curralinho, distrito Vila do Piriá, estado do Pará. Nosso percurso investigativo tem como objetivo analisar a infância, quem são e como vivem as crianças ribeirinhas da Amazônia Marajoara e que práticas culturais vivenciam no seu cotidiano. A problematização consiste na seguinte indagação: que práticas culturais fazem parte do cotidiano das crianças ribeirinhas da Amazônia Marajoara? A referência teórico-metodológica centra-se na Sociologia da Infância, na Teoria Crítica e nos Estudos do Cotidiano. A pesquisa se constitui por meio de uma abordagem qualitativa focada numa etnografia com crianças. Nossa opção por esta metodologia se deu em virtude de ela responder com maior efeito às nossas expectativas no sentido de dar voz à criança e de harmonizar a pesquisa de maneira que conseguisse capturar a voz da criança-ator. O estudo possibilitou a análise da identidade, da cultura, do cotidiano, do tempo de ser criança em condições objetivas.

Palavras-chave: Infâncias. Crianças ribeirinhas. Práticas culturais.

\footnotetext{
* Doutoranda do Programa de Pós-Graduação em Educação da PUC Minas. É Professora da Universidade Federal do Pará (UFPA)/Instituto de Ciências da Arte (ICA)/Escola de Teatro e Dança (ETDUFPA). Mestre em Educação pela Universidade Adventista de São Paulo (UNASP). Especialista em Currículo e Avaliação da Educação Básica pela Universidade Estadual do Pará (UEPA) e Arte-educação pela PUC Minas. Graduada em Pedagogia e Serviço Social pela Universidade Federal do Pará (UFPA).

** Pedagoga, Mestre em Educação pela UPFA e Doutoranda do Programa de Pós-Graduação em Educação da UFPA.

${ }^{1}$ São conhecimentos
} 


\title{
CHILDHOODS AND THE RIVERINE CHILDREN OF MARAJOARA AMAZON: LANGUAGES AND CULTURAL PRACTICES
}

\begin{abstract}
"Childhoods and the riverine children of Marajoara Amazon: languages and cultural practices" is part of a broader research on childhood in the Amazon, in progress. The research was conducted with twenty (20) children, aged 5-11 years living in the city of Curralinho, Piriá Village district, state of Pará. Our investigative course aims to analyze childhood, who they are, and how riverine children Marajoara Amazon live and what cultural practices they experience daily. The problematization is the following question: which cultural practices are parts of the daily lives of local children of Marajoara Amazon? The theoretical and methodological reference focuses on the sociology of childhood, in Critical Theory and Daily Life Studies. The research is through a qualitative approach focused on ethnography with children. Our choice for this methodology was due to it responding with greater effect to our expectations in order to give voice to children and to harmonize research so that he could capture the voice of the child-actor. The study allowed the analysis of identity, culture, daily life, the time of being children in objective conditions.
\end{abstract}

Keywords: Childhoods. Riverine Children. Cultural Practices.

\section{INTRODUÇÃO}

A partir da ideia de que as crianças têm muito a dizer de si e do mundo em que vivem é que adentramos a Amazônia, especificamente a Amazônia Marajoara, estado do Pará, município de Curralinho, distrito Vila do Piriá, onde buscamos subsídios que nos possibilitassem analisar, por meio de uma concepção crítica, a infância e as crianças desse território, sujeitos que possuem a "sabedoria de vida", na qual as "[...] crianças circulavam cotidianamente nas marés do rio, [...], traduzindo um cotidiano com práticas oriundas de vivências compartilhadas entre familiares e comunidade. [...]" (OLIVEIRA, 2015, p. 74)

A realidade da população amazônica, especificamente da criança dessa região, tem se mostrado cruel diante da situação de abandono a que estão submetidas: "[...] exploração de crianças por aliciadores, o trabalho infantil, a prostituição infantil estimulada também pela família, crianças expostas a todo tipo de violência, crianças escalpeladas, ausência de educação de qualidade, [...]" (LOPES, 2012, p. 21) esse é o quadro vivido pelas crianças ribeirinhas do Norte do Brasil. Sobre esse aspecto Arroyo (2012, p. 31) chama a atenção ao considerar que “[...]. As infâncias [...] tão

\footnotetext{
${ }^{2}$ São conhecimentos que se aprendem no cotidiano, que se constroem nas relações que a própria comunidade estabelece com os seus - homens, mulheres e crianças.
} 
precarizadas, tão vulneráveis também são humanas", ou seja, a condição de perversidade a que estão submetidas exige um tratamento mais humano, independente do lugar onde estejam, até numa região tão complexa como a Amazônica, na verdade "estão exigindo ser reconhecidos humanos" (idem).

\section{METODOLOGIA DA PESQUISA}

Neste lugar de diversidade e contraste emerge nossa investigação - infầncia na Amazônia, quem são e como vivem as crianças ribeirinhas da Amazônia Marajoara e que práticas culturais vivenciam no seu cotidiano. O estudo considera que o lugar é "O território onde se desdobram e se repetem dia a dia os gestos elementares das "artes de fazer" é antes de tudo o espaço doméstico, a casa da gente. [...]" (CERTEAU, 2013, p. 203). Para Certeau (2013) o lugar habitado por pessoas, por determinado período, terá o seu jeito, a sua forma de organização que se constrói a partir dos objetos e dos costumes, portanto, compreendemos que a criança ribeirinha estabelece seu lugar, que se constitui sua casa, onde as culturas infantis se fazem e se redimensionam. As crianças deste lugar “[...] formam o seu próprio mundo de coisas, mundo pequeno inserido em um maior. [...]." (BENJAMIN, 1984, p. 77)

O lugar também se organiza pelo tempo. O tempo amazônico é o do movimento das águas; do vai e vem das marés; do tempo de descida e ou subida dos barcos, canoas, casquinhos ${ }^{3}$, balsas, rabetas $^{4}$, rabudos ${ }^{5}$ e lanchas; do ir e vir da população. O tempo que também se arraiga no vivenciar das culturas infantis presentes no brincar, no tomar banho de rio, de correr sem destino certo - de simplesmente viver, com suas alegrias e adversidades. A vida não é algo estático, principalmente para as crianças, mas ela se refaz, dá novo sentido às pessoas e aos objetos, nada acontece sempre do mesmo jeito. "Ao estarem às margens de rios, os ribeirinhos elaboram maneiras próprias de vida, repletas de uma cultura identificada pela sua forma de sobrevivência e transcendência. [...]." (OLIVEIRA, 2015, p. 76)

Afinal, o que tem nos instigado a investigar a infância e a criança com suas práticas culturais da Amazônia? É certo que um lugar com uma rica biodiversidade, que se caracteriza por ser um espaço grandioso, que só no Brasil possui uma área de $5.035 .772,54 \mathrm{~km}^{2}$ e atravessa 9 (nove) estados, há de gerar uma diversidade ambiental e cultural, na qual a criança está imersa, e que ainda se tem pouca pesquisa com ela, ou seja, sabemos pouco ou nada da criança deste lugar. (CARVALHO, 2014)

\section{AS CRIANÇAS E AS INFÂNCIAS}

\footnotetext{
${ }^{3}$ Embarcações de pequeno porte impulsionadas a remo, e que conduzem uma ou duas pessoas.

${ }^{4}$ Embarcações de pequeno porte, que dispõem de um motor instalado no centro.

${ }^{5}$ Embarcações de pequeno porte que dispõem de um motor instalado em uma de suas extremidades (popa).
} 
Procuramos analisar a condição da infância na região Norte do Brasil, por considerarmos ser relevante para a apreensão de quem são e como vivem as crianças ribeirinhas da Amazônia Marajoara, e que práticas culturais vivenciam no seu cotidiano. Práticas culturais aqui entendidas, “[...] como campos de conhecimento da criança. [...].”, sendo esta concebida "[...] na sua condição social de ser histórico, político e cultural" (ALVES, 2014, p. 35). Neste contexto, “instauram-se ideias, valores, costumes e conhecimentos que serão transmitidos por meio das linguagens verbais e não verbais". (FRIEDMANN, 2013, p. 64)

As culturas infantis na Amazônia Marajoara são híbridas, originárias da formação cultural familiar do pai, da mãe, da cultura constituída pela própria criança que advém de sua natureza, da cultura escolar, de seus grupos sociais, do brincar, da interação com o meio ambiente, onde "Cada ser humano "carrega" uma cultura que irá se misturar com as outras. Cada um "herda", reproduz, adentra e incorpora elementos das diversas culturas" (FRIEDMANN, 2013, p. 63). Compreender a criança produzindo cultura é percebê-la na sua cotidianidade, ou seja, na sua interação com o mundo.

Em todos os espaços da Amazônia Marajoara (na floresta, na beira dos rios, nos campos de natureza, no igapó e na várzea) as crianças estão presentes, construindo suas histórias e suas culturas e ou dando um novo sentido a elas (HAGE, 2014), também “está repleta dos mais incomparáveis objetos da atenção e da ação das crianças. [...]”. (BENJAMIN, 1984, p, 77)

Para a compreensão da infância e da criança da Amazônia ribeirinha, se fez necessária uma incursão no seu cotidiano para trazer à tona a identidade e as práticas culturais dos meninos e meninas deste lugar. Ribeiro (2006) nos referenda que a identidade de um povo não é definida pelos limites do seu território, mas pelo contíguo de particularidades que faz dele um grupo com identidade própria, se diferenciando dos demais grupos.

Compreender a infầncia amazônica é abrir possibilidades para entender a identidade do ser que “[...] cria, renova, interfere, transforma, reformula, sumariza, ou alarga sua compreensão das coisas, suas ideias, por meio do que vai dando sentido a sua existência” (LOUREIRO, 2007, p. 11).

\section{O LUGAR E SUA HISTÓRIA}

Durante a investigação percebemos a importância sócio-histórica que Vila do Piriá teve na região a partir dos meados do século $\mathrm{XX}$, como grande exploradora, beneficiadora e exportadora de madeiras de área de várzea. Como a maior comunidade ribeirinha da região e um distrito legalmente constituído, a Vila do Piriá possui o segundo maior colégio eleitoral do município, ficando atrás apenas do distrito Sede - Curralinho, constituindo-se como um polo de comércio, atendimento de 
saúde e educação para outras comunidades do entorno, com índice populacional menor, que se localizam ao longo do rio Piriá e afluentes. Conta com uma população de 9.869 habitantes, dos quais 3.757 são crianças na faixa etária de 0 a 11 anos, o que corresponde a 38,06\% da população. Na faixa etária de 5 a 11 anos há 1.839 crianças, o que corresponde a 18,63\% da população (INSTITUTO BRASILEIRO DE GEOGRAFIA E ESTATÍSTICA, 2010), as quais se constituíram em interlocutores de nossa pesquisa.

Esses levantamentos foram determinantes na decisão de realizarmos a pesquisa de campo nessa comunidade. Nosso interesse foi conhecer as crianças ribeirinhas por meio delas próprias, considerando que se fez necessário colocá-las como protagonistas da sua história, como nos fundamenta Alves (2014) ao completar,

[...] que é preciso dar voz às crianças, conhecer quem são, como vivem, como é seu grupo de interação, quais suas preferências e o que elas pensam a respeito de si mesmas, das relações com o seus pares e com os adultos, acerca do mundo em que vivem entre outras questões. [...]. (ALVES, 2014, p. 40)

Portanto, foi acreditando no potencial que a criança ribeirinha da Amazônia Marajoara possui de dizer de si e do mundo na qual está inserida é que nos lançamos a campo, por meio de estratégias metodológicas, centradas principalmente nas observações e narrativas orais, objetivando saber como se dá a constituição da infância na Amazônia, quem são e como vivem as crianças ribeirinhas do Norte do Brasil e que práticas culturais vivenciam no seu cotidiano, mas “[...]. Sem a pretensão de "ver" ou aprender a totalidade, o desafio é não desconsiderar nem desconhecer práticas [...] cotidianas em sua complexidade, pluralidade, diversidade e singularidade. [...]” (SAMPAIO, 2003, p. 17).

Deste modo, nossa investigação desenvolveu-se com crianças de 5 a 11 anos, que tinham o domínio da oralidade e conseguiam proclamar de forma intensa a sua maneira de ver e ser criança nessa região de água e floresta, como também de expressar corporalmente, com propriedade, os seus modos de vida - as práticas culturais. Outro fator que levamos em consideração foi o fato de as crianças estarem constantemente se movimentando pelas vias da comunidade, indo ou retornando da escola, da igreja, brincando, trabalhando e ou executando tarefas a pedido dos adultos, enfim, desenvolvendo as mais diversas ações. Foi nestes espaços e momentos que realizamos a pesquisa de campo.

\section{ASPECTOS METODOLÓGICOS}

A investigação desenvolveu-se com base numa abordagem qualitativa, por considerarmos ser esta a que mais se aproxima de nossos objetivos. Essa abordagem "trabalha com o universo dos significados, dos motivos, das aspirações, das crenças, dos valores e das atitudes” (MINAYO, 2012, 
p. 21), portanto, nos possibilitando um trilhar na realidade social do sujeito-criança que "[...] se distingue não só por agir, mas por pensar [...] o que faz e por interpretar suas ações dentro e a partir da realidade vivida e partilhada com seus semelhantes. [...]”.

No contexto da abordagem qualitativa, nossa opção por uma etnografia com crianças se deu em virtude de esta responder com maior efeito às nossas expectativas no sentido de dar voz à criança e de harmonizar a pesquisa de maneira que conseguisse capturar essa voz manifestada pelo riso, pelo grito, pelo sussurro, pelo choro, pelo silêncio, bem como pelas expressões corporais e práticas culturais. A etnografia se tornou parte integrante desta investigação por se constituir numa tendência que se preocupa com "o significado que têm as ações e os eventos para as pessoas ou os grupos estudados”. (ANDRÉ, 1995, p. 19).

Deste modo construímos uma etnografia com crianças ribeirinhas da Amazônia Marajoara por entendermos que esse enfoque possibilitou capturar com clareza os desejos e aspirações das crianças, uma vez que "[...] a etnografia é uma metodologia particularmente útil porque permite captar uma voz mais directa das crianças e sua participação na produção de dados sociológicos; [...]" (QVORTRUP, 1996 apud FERREIRA, 2004, p. 18). Nesse contexto amazônico, a etnografia nos permitiu trabalhar com um grupo social ainda pouco conhecido pelas pesquisas acadêmicas, trazendo às análises sua cultura plural.

Assim sendo, a etnografia consentiu caminharmos por meio de estratégias lúdicas, literárias e iconográficas para apreendermos como as crianças movimentam a sociedade, constroem e dão um sentido novo às coisas e às relações que eles estabelecem. Nesta perspectiva, Rocha (2008) considera que

[...] aprender mais sobre as maneiras como a própria sociedade e a estrutura social dão conformidade às infâncias; [...] o que elas produzem das estruturas ou o que elas próprias produzem e transformam através de sua ação social; sobre os significados sociais que estão sendo socialmente aceites e transmitidos e [...] o modo como o homem e mais particularmente as crianças - como seres humanos novos, de pouca idade - constroem e transformam o significado das coisas e as próprias relações sociais. (ROCHA, 2008, p. 48)

Pelos caminhos da etnografia tivemos a possibilidade de refletir como as crianças da Amazônia se estabelecem nesse espaço de exuberância natural, mas ao mesmo tempo, um espaço marcado pela pobreza e miséria da população excluída do seu próprio chão.

A fim de que pudéssemos focar a criança numa dada realidade, muito particular - a amazônica - fez-se necessário pensar na Sociologia da Infância, com base em um paradigma contemporâneo, que possibilitasse discutir a criança desse lugar e a diversidade cultural que a envolve, considerando “[...] as múltiplas vozes, temporalidades, histórias na contemporaneidade; entender que a cultura e os modos de vida dos ribeirinhos têm suas próprias histórias" (LIMA, 2011, p. 53), que precisam ser 
contadas e registradas.

Como conteúdo basilar para a compreensão dessa realidade, consideramos os estudos de Ferreira (2004), baseados nas pesquisas de James \& Prout, Qvortrup e Sarmento, que tratam de um novo paradigma da Sociologia da Infância, na qual a infância é entendida como fenômeno social e a criança como um ator social que diz de si, do seu lugar, da sua cultura e da sua história.

Nosso estudo se desenvolveu, portanto, sob este novo paradigma da Sociologia da Infância, que vê a infância como categoria legítima e as crianças como sujeitos participativos que são, respeitando suas dimensões social, cognitiva e afetiva, e que produzem cultura e partilham no coletivo suas experiências (FERREIRA, 2004). É nessa perspectiva que buscamos analisar a infância e as crianças ribeirinhas amazônicas ao observarmos que elas se constituem a partir de suas práticas culturais, geralmente associadas à cultura local, como nos afiança Silva (2007),

[...]. A compreensão das formas como essas comunidades estruturam suas práticas sociais, estabelecem relações com os recursos da floresta e se organizam socialmente, torna-se importante para uma aproximação dialógica entre saber constituído e saberes práticos e identificar outras possibilidades de relação sociedade natureza a partir da contextualização da cultura local. (SILVA, 2007, p. 48)

As práticas culturais das crianças ribeirinhas são marcadas por suas vivências no ato de brincar, na escola, na igreja, na via pública, na sua forma de expressão corporal, de gesticular, na oralidade, nas manifestações culturais, nas relações que estabelecem consigo, com seus pares, com os adultos e com a natureza, ou seja, tais vivências traduzem emoções, como nos referenda Benjamin (1984, p. 43) ao afirmar que “[...] todas as manifestações na vida infantil não pretendem outra coisa senão conservar em si os sentimentos essenciais. [...]", sentimentos que dizem o modo de ser e de viver da criança amazônida.

As crianças da Vila do Piriá vivem cercadas pela natureza, “constroem e [...] [modificam] o significado das coisas e as próprias relações sociais” (ROCHA, 2008, p. 48 - grifo nosso). A ideia de CONSTRUIR e MODIFICAR advém da compreensão de que elas são sujeitos plenos de direitos, com capacidades de expor suas opiniões com clareza, pessoas que produzem cultura e ao mesmo tempo são nelas produzidas, são críticas e subvertem a ordem daquilo que consideram ser necessário a sua vida, ao seu bem-estar, mesmo que haja uma ordem social adultocêntrica dizendo o contrário (KRAMER, 2011).

A relação estabelecida com a natureza mostra que o sujeito-criança ribeirinho "Acostumado desde pequenino à água e à mata, encontra-se seguro quando está brincando, nadando, pescando numa canoa, nos rios ou andando pela floresta. [...]” (SPÍNOLA, 1997, p. 9), ou seja, sente-se seguro desenvolvendo suas práticas culturais.

As crianças ribeirinhas vivenciam a natureza de maneira muito particular; é como se elas inalassem o cheiro das plantas, raízes e frutos que exalam no suor quando correm nas pontes e sobem nas palmeiras de açaí, incorporassem as expressões do balanço das árvores e do sobe e desce das 
marés, traduzidas no bailado das brincadeiras que acontecem no rio; como se o canto dos pássaros fosse sua própria voz, que canta e encanta para dizer que sabem contar muito e de muita coisa da cultura e da história dos que vivem na ribeira dos rios. Nessa perspectiva Pojo e Vilhena (2013) consideram que

O rio é a rua, e o quintal é o espaço da interlocução de vivências de uma geração que brinca de nadar no rio, subir na árvore, pular da ponte no rio, [...]. Traduzem, afirmam e recriam formas culturais por meio da linguagem, aliás, expressam pela oralidade todo o conhecimento e sabedoria que aprendem desde cedo. (POJO; VILHENA, 2013, p. 143)

A comunidade ribeirinha de Vila do Piriá, localizada às margens do rio Piriá, é o local onde as crianças dessa investigação residem. Considerada área interiorana, de várzea e igapó, apresenta características próprias de um lugar em que "Outros valores são mais presentes, outros modos de organizar a vida cotidiana e relações diferentes entre as crianças e os adultos. [...]” (MORAES; ALVES, 2014, p. 304) se estabelecem. Portanto, valores e diferenças aqui tratados dizem respeito ao modo particular, como os sujeitos desse lugar, em especial as crianças ribeirinhas, vivenciam seus saberes, suas práticas culturais, modos de vida centrados nas relações que estabelecem com o rio e a floresta. (SILVA, 2007)

Ao longo desse estudo nos deparamos com a multiplicidade de práticas culturais vivenciadas pelas crianças na Vila do Piriá, práticas que se constituem “[...] modos específicos de apreensão do mundo do grupo geracional da infância, [...]” (MORAES; ALVES, 2014, p. 305).

As crianças têm a capacidade de dizer do seu lugar de uma maneira simples, concreta e sensível, dando-nos a possibilidade de problematizá-las para que não fiquem no sensus communis como crianças "in-fans" - sem voz - mas que as percebamos sob um novo patamar, aquele em que a criança dá um novo sentido à ordem das coisas, que propicia ver a situação a partir de muitos ângulos, que nos faz aprender a aprender, que nos mostra que a Amazônia é um espaço seu e do outro, um lugar ímpar com culturas singulares. Aprender com as crianças ribeirinhas é aprender a olhar a vida sob outro prisma - pelo avesso, como nos referenda Kramer (2011) ao considerar que,

\footnotetext{
Aprender com as crianças pode ajudar a compreender o valor da imaginação, da arte, da dimensão lúdica, da poesia, de pensar adiante. Entender que as crianças têm um olhar crítico que vira pelo avesso a ordem das coisas, que subverte o sentido de uma história, que muda a direção de certas situações, exige que possamos conhecer nossas crianças, o que fazem, de que brincam, como inventam, de que falam. [...]. Há que aprender com as crianças a olhar e virar pelo avesso, a subverter, a tocar o tambor no ritmo contrário da banda militar, de maneira que as pessoas, em vez de gritar, obedecer ou marchar, comecem a bailar. (KRAMER, 2011, p. 117)

Se a cultura surge de todo um modo de vida, é de esperar que a cultura [...] varie segundo diferenças ecológicas, além das sociais; diferenças no ambiente físico implicam diferenças na cultura material e estimulam também diferentes atitudes. [...]. (BURKE, 2010, p. 59)
} 
As crianças ficam por horas na beira do rio, nos pequenos trapiches ${ }^{6}$, contando coisas da vida, brincando, rindo, encarnando ${ }^{7}$ com o outro, tomando banho e pescando ${ }^{8}$, a qualquer tempo. A transmissão cultural se realiza não apenas pela forma como as crianças aprendem, mas também pela maneira como elas transmitem o conhecimento (HELLER, 1987). Elas sofrem influências culturais do seu meio, ao mesmo tempo em que contribuem para a afirmação da cultura local, pois estão inseridas num dado contexto social e também vivem num determinado momento histórico (MORAES; ALVES, 2014).

Nesse espaço multicultural buscamos mostrar como vivem as crianças ribeirinhas e como estabelecem suas práticas culturais, entrelaçadas de saberes que de alguma forma orientam seus aprendizados.

Consideramos que a criança ribeirinha da Amazônia faz parte de uma sociedade complexa e heterogênea, com culturas e modos diferentes de vida, que possibilitam a percepção de que ela "não é uma unidade culturalmente homogênea" (GRAMSCI, 1950 apud BURKE, 2010, p. 57), mas é um sujeito embebido nas suas culturas, que confronta a realidade, que subverte o status quo, pois “[...] é no convívio e no confronto das diferenças que as crianças aprendem, desde pequenininhas, a respeitar e a valorizar a diversidade sociocultural, tão importante na cultura plural na qual vivemos". (REIS; SANTOS; XAVIER, 2012, p. 12)

Ao colocarmos em evidência o que as crianças ribeirinhas dizem de si, do outro e do mundo, consideramos a infầncia “[...] um componente da cultura e da sociedade; [...]”; “[...] sinônimo de um grupo social concreto, uma parcela importante da população [...], com características específicas”; “[...] é um meio social e natural no qual evoluem as crianças concretas" (BELLONI, 2009, p. 127).

As crianças ribeirinhas possuem um jeito muito próprio de externar suas ideias, encontrando na oralidade sua melhor forma de expressão. Falar de suas vivências seduz o ouvinte, contando histórias, causos, com muita emoção, que se traduz numa fala elaborada com um linguajar próprio do lugar e gesticulações que dão ênfase e ajudam o outro a entender o que estão a dizer. É pela linguagem oral que elas dizem de si, da sua cultura, do seu universo. Portanto, “[...]. A linguagem falada é, assim, a esfera da manifestação livre e primordial da criatura; [...]” (BENJAMIN, 2011, p. 219), ou seja, do sujeito-criança. Também Certeau (2014) observa que “A linguagem produzida por uma categoria social [Infância] dispõe do poder de estender suas conquistas às vastas regiões do seu meio ambiente, $[. .$.$] " (CERTEAU, 2014, p. 89, grifo nosso), constituindo-se a linguagem em um$ instrumento de luta capaz de dar novo significado à vida dos sujeitos-atores da Amazônia.

\footnotetext{
${ }^{6}$ Atracadouro geralmente feito de madeira utilizada pelas embarcações para embarque e desembarque de pessoas e mercadorias.

${ }^{7}$ Gozando, fazendo pouco, pilheriando. (SOBRAL, 2014)

${ }^{8}$ Pescar, para as crianças, é pegar no rio peixes, crustáceos, quelônios e répteis.
} 


\section{CONSIDERAÇÕES FINAIS}

A oralidade dá o tom da vida cotidiana para o ribeirinho, fluindo naturalmente na voz gritante, rouca, aguda e amena dos pequenos, não "[...] como um reino de palavras, mas como algo que se dissolve nos seus sons e nas suas vozes" (BENJAMIN, 2011, p. 220).

Não somente a oralidade é a linguagem das crianças ribeirinhas, mas existem outras linguagens que se expressam das mais diversas maneiras no seu cotidiano e ecoam no mundo da floresta e das águas.

O corpo se torna também sua voz, a gesticulação das mãos e o tronco num constante movimento produzem um modo específico de comunicação da criança desse território, como nos diz Benjamim (2013, p. 18) "A linguagem gestual vai muito mais longe aqui do que em qualquer outro lugar [...]".

O olhar também se constitui em uma linguagem específica das crianças ribeirinhas. Através do olhar elas expressam confiança, desconfiança, alegria, tristeza, decepção, carinho, aceitação ou reprovação diante das várias situações do dia a dia. Embora "As pessoas que estão encurraladas no recinto deste país perderam o olhar para o contorno da pessoa humana. [...]” (BENJAMIN, 2012, p. 22), a criança ribeirinha da Amazônia Marajoara possui a leveza e a inteligência no olhar, para perceber o outro e no outro a beleza da amizade e do respeito as suas particularidades.

Um olhar meio que sem graça, cabisbaixo, arregalado, maroto, brilhante, surpreso e lacrimejante das crianças ribeirinhas marca sua identidade e sua personalidade, como se estivessem expressando por meio de palavras um tanto de sua história.

Nada passa despercebido aos olhares das crianças, desde uma simples jacinta ${ }^{9}$ posando numa tora de madeira até uma movimentação política (eleição) na Vila do Piriá, tudo está na mira dos meninos e meninas deste território. Eles reúnem com seus pares em qualquer lugar (beira do rio, porta das casas, na ponte, na frente da escola e da creche, na igreja, na quadra), enfim, nos mais diversos espaços e com suas linguagens (oral, corporal, gestual e olhar) questionam, opinam, dão vazão a suas emoções, "[...] coloca em pauta os problemas do seu dia a dia, mesmo os mais difíceis de serem solucionados, buscando alternativas para a sua resolução" (ANDRADE, 2013, p. 19), como salienta Benjamin (1984) ao considerar que “[...]. Todo aquele que questionar sua vida com a exigência mais elevada encontrará seus próprios mandamentos. Libertará o futuro de sua forma desfigurada, reconhecendo-a no presente". (BENJAMIN, 1984, p. 41)

Compreendemos, assim, que as crianças ribeirinhas da Amazônia Marajoara, com suas infâncias, são sujeitos do presente, dispostos e motivados a dar um novo sentido ao seu dia a dia, que

\footnotetext{
${ }^{9}$ Libélula.
} 
se compõe de muitas linguagens e práticas culturais.

\section{REFERÊNCIAS}

ALVES, Laura Maria Silva Araújo. A constituição do discurso narrativo polifônico da criança: traços da mitopoética amazônica. In: ALVES, Laura Maria Silva Araújo (Org.). Educação infantil e estudos da infância na Amazônia. Belém: EDUFPA, 2007. p.133-167.

ALVES, Laura Maria Silva Araújo. A infância em construção: as fontes de investigação. In: ARAÚJO, Sônia Maria da Silva; ALVES, Laura Maria Silva Araújo; BERTOLO, Sônia de Jesus Nunes (Org.). Pesquisa e educação na Amazônia: reflexões epistemológicas e politicas. Belém: EDUEPA, 2014. p. 35-52.

ANDRADE, Simei Santos. O lúdico na vida e na escola: desafios metodológicos. Curitiba: Appris, 2013.

ANDRÉ, Marli Eliza Dalmazo Afonso de. Etnografia da prática escolar. Campinas: Papirus, 1995. (Série Prática Pedagógica)

ARROYO, Miguel G. Corpos precarizados que interrogam nossa ética profissional. In: ARROYO, Miguel G.; SILVA, Maurício Roberto da (Org.). Corpo-infância: exercícios tensos de ser criança; por outras pedagogias dos corpos. Petrópolis: Vozes, 2012. p. 23-53.

BELLONI, Maria Luiza. O que sociologia da infância. Campinas: Autores Associados, 2009. (Acadêmico de bolso)

BENJAMIN, Walter. Reflexões: a criança, o brinquedo, a educação. Tradução de Marcus Vinicius Mazzari. São Paulo: Summus, 1984. (Novas buscas em educação; v. 17)

BENJAMIN, Walter. Origem do drama trágico alemão. Edição e Tradução de João Barrento, 1. ed., Belo Horizonte: Autêntica, 2011.

BENJAMIN, Walter. Rua de mão única. Tradução de Rubem Rodrigues Torres Filho e José Carlos Martins Barbosa, 6. ed. rev. São Paulo: Brasiliense, 2012. (Obras Escolhidas v. 2)

BENJAMIN, Walter. Imagens de pensamento/sobre o haxixe e outras drogas. Edição e Tradução de João Barrento. Belo Horizonte: Autêntica, 2013. (Coleção Filô/Benjamin; 4)

BURKE, Peter. Cultura popular na idade moderna: Europa 1500-1800. Tradução de Denise Bottmann. São Paulo: Companhia das Letras, 2010.

CARVALHO, Ana Maria Orlandina Tancredi. As produções acadêmicas sobre infância na Amazônia. In: ARAÚJO, Sônia Maria da Silva; ALVES, Laura Maria Silva Araújo; BERTOLO, Sônia de Jesus Nunes (Org.). Pesquisa e educação na Amazônia: reflexões epistemológicas e políticas. Belém: EDUEPA, 2014. p. 25-33

CERTEAU, Michel; GIARD, Luce. Espaços Privativos. In: CERTEAU, Michel; GIARD, Luce; MAYOL, Pierre. 2. A invenção do cotidiano: morar, cozinhar. Tradução de Ephraim F. Alves e Lúcia Endlich Orth. 12. ed. Petrópolis: Vozes, 2013. p. 203-207.

CERTEAU, Michel. 1. A invenção do cotidiano: artes de fazer. Tradução de Ephraim Ferreira Alves. 
21. ed. Petrópolis: Vozes, 2014.

FERREIRA, Manuela. A gente gosta é de brincar com os outros meninos! relações sociais entre crianças num Jardim de Infầncia. Porto: Edições Afrontamento, 2004.

FRIEDMANN, Adriana. Linguagens e culturas infantis. São Paulo: Cortez, 2013.

HAGE, Salomão Mufarrej. Educação do campo na Amazônia: retratos e desafios das escolas multisseriadas na Amazônia paraense. In: ARAÚJO, Sônia Maria da Silva; ALVES, Laura Maria Silva Araújo; BERTOLO, Sônia de Jesus Nunes (Org.). Pesquisa e educação na Amazônia: reflexões epistemológicas e politicas. Belém: EDUEPA, 2014. p. 163-176.

HELLER, A. O Cotidiano e a história. São Paulo: Paz e Terra, 1987.

INSTITUTO BRASILEIRO DE GEOGRAFIA E ESTATÍSTICA. Pará Curralinho. Rio de Janeiro: IBGE, 2016. Disponível em:

$<$ http://www.cidades.ibge.gov.br/xtras/perfil.php?lang=\&codmun=150280\&search=para|curralinho >. Acesso em: 25 de março de 2016.

KRAMER, Sonia. Infância, cultura contemporânea e educação contra a barbárie. In: BAZÍLIO, Luiz Cavalieri; KRAMER, Sonia. Infância, educação e direitos humanos. 4. ed. São Paulo, Cortez, 2011. p. 93-151.

LIMA, Natamias Lopes de. Saberes culturais e modos de vida de ribeirinhos e sua relação com o currículo escolar: um estudo no município de Breves/PA. 2011. 159f. Dissertação (Mestrado) Instituto de Ciências da Educação da UFPA. Universidade Federal do Pará, Belém, 2011.

LOPES, Adrea Simone Canto. A construção da identidade da infância na Amazônia ribeirinha: Ilha de Cotijuba Belém-Pará. 2012. 209f. Tese (Doutorado) - Faculdade de Ciências Econômicas da UFRS. Universidade Federal do Rio Grande do Sul, Porto Alegre.

LOUREIRO, João de Jesus Paes. A conversão da semiótica: na arte e na cultura. Edição trilíngue. Belém: EDUFPA, 2007.

MINAYO, Maria Cecília de Souza. O desafio da pesquisa social. In: DESLANDES, Suely Ferreira; GOMES, Romeu; MINAYO, Maria Cecília de Souza (Org.). Pesquisa social: teoria, método e criatividade. 32. ed. Petrópolis: Vozes, 2012. p. 9-29.

MORAES, Elisangela Marques; ALVES, Laura Maria Silva Araújo. A infância camponesa na Amazônia na visão de crianças de um assentamento no Pará. In: ARAÚJO, Sônia Maria da Silva; ALVES, Laura Maria Silva Araújo; BERTOLO, Sônia de Jesus Nunes (Org.). Pesquisa e educação na Amazônia: reflexões epistemológicas e políticas. Belém: EDUEPA, 2014. p. 112-128.

OLIVEIRA, José Sávio Bicho de. Os ribeirinhos da Amazônia: das práticas em curso á educação escolar. Disponível em: <http://www.revista.unisal.br/ojs/index.php/educacao/article/view/390>. Revista de Ciências da Educação, UNIASAL, Americana/SP, Ano XVII, n. 32, p. 73-95, jan./jun. 2015.

POJO, Eliana Campos; VILHENA, Maria de Nazaré. Crianças ribeirinhas da Amazônia paraense. In: SILVA, Isabel de Oliveira e; SILVA, Ana Paula Soares da; MARTINS, Aracy Alves (Org.). Infâncias do campo. Belo Horizonte: Autêntica editora, 2013. p. 135-148. (Coleção Caminhos da Educação no Campo) 
REIS, Magali; SANTOS, Lorene dos; XAVIER, Maria do Carmo. Crianças e infâncias: educação, conhecimento, cultura e sociedade. In: REIS, Magali; XAVIER, Maria do Carmo; SANTOS, Lorene dos (Org.). Crianças e infâncias: educação, conhecimento, cultura e sociedade. São Paulo: Annablume, 2012. p. 7-18.

RIBEIRO, Darcy. O povo brasileiro: a formação e o sentido do Brasil. São Paulo: Companhia das Letras, 2006.

ROCHA, Eloisa Acires Candal. Por que ouvir as crianças? Algumas questões para um debate científico multidisciplinar. In: CRUZ, Silvia Helena Vieira (Org.). A criança fala: a escuta de crianças em pesquisa. São Paulo: Cortez, 2008.

SAMPAIO, Carmen Sanches. Compreender o compreender das crianças em seus processos alfabetizadores. In: GARCIA, Regina Leite (Org.). Método: pesquisa com o cotidiano. Rio de Janeiro: DP\&A Editora, 2003.

SILVA, Maria das Graças da. Práticas educativas ambientais, saberes e modos de vida locais. Revista Cocar, Belém, v. 1, n. 1, p. 47-57, 2007.

SOBRAL, Raymundo Mário. Dicionário Papachibé: a linguagem paraense. Belém: Santo Antonio, 2014. v. 5.

SPÍNOLA, Henriqueta Barbosa. O ribeirinho: ontem e hoje na defesa do peixe no Amazonas.1997.192f. Dissertação (Mestrado em Educação) - Faculdade de Educação. Universidade Estadual de Campinas, Campinas/SP, 1997.

Recebido em: 19/10/2016

Aprovado em: 20/12/2016 